\title{
Capparis Aegyptia as a green inhibitor for aluminum corrosion in alkaline media
}

\author{
M.A. Al-Qudah,* H.G. AL-Keifi, I.F. Al-Momani and S.T. Abu-Orabi \\ Department of Chemistry, Faculty of Science, Yarmouk University, Irbid, Jordan \\ *E-mail: mahmoud.qudah@yu.edu.jo
}

\begin{abstract}
The study of metal corrosion is of particular importance for the environment, economy and industry. Several methods have been used to control corrosion of metals. However, plant extracts are considered among the best choices as they are environmentally safe, inexpensive and renewable. In this study, the inhibition effect of Capparis Aegyptia extract on the corrosion of aluminum in $1 \mathrm{M}$ sodium hydroxide $(\mathrm{NaOH})$ was investigated. Both weight-loss measurements and electrochemical polarization methods were used. The results show that C. aegyptia extract is a good corrosion inhibitor. The inhibition efficiency increases with inhibitor (C. aegyptia extract) concentration and slightly increases with temperature. The inhibition efficiency reaches a maximum value of $93.8 \%$ with the highest extract concentration at $25^{\circ} \mathrm{C}$. The adsorption of C. aegyptia extract on aluminum surface obeys Langmuir and Temkin adsorption isotherms. The thermodynamic adsorption free energy $\left(\Delta G_{\text {ads }}^{0}\right)$ value and sign were indicative of the physisorption of $C$. aegyptia extract molecules on the aluminum surface. Moreover, the thermodynamic parameters $\left(\Delta H^{*}, \Delta S^{*}\right.$ and $\left.E_{\mathrm{a}}\right)$ of the adsorption process were calculated and discussed. The electrochemical polarization study showed that $C$. aegyptia extract act as a mixed-type inhibitor cathodic and anodic. Moreover, surface morphology was analyzed by scanning electron microscopy (SEM) technique. SEM results provided confirmatory evidence of the improved surface condition, due to the adsorption, for the corrosion protection.
\end{abstract}

Keywords: C. aegyptia, green inhibitor, aluminum, electrochemical polarization, weight loss.

Received: November 30, 2019. Published: February 5, 2020

doi: $\underline{10.17675 / 2305-6894-2020-9-1-12}$

\section{Introduction}

The study of natural products of plant origin as inexpensive, eco-friendly corrosion inhibitors is an essential field of study. The extracts from their leaves, barks, seeds, and roots comprise of a mixture of organic compounds and some have been reported to function as effective inhibitors of metal corrosion [1-3]. The presence of heteroatoms in the structure of inhibitory molecules such as $\mathrm{O}, \mathrm{N}, \mathrm{S}$; enhance the adsorption process and inhibition efficiency $[4,5]$. Recent literature has shown that plant materials, such as Salvia judica [6], Sinapis Alba [7], Plumbago Europae [8], Mesembryanthemum nodiflorum [9], 
Inula viscosa [10], Lupinus varius [11] and Capparis spinosa [12,13] are effective inhibitors for aluminum in alkaline solution. The corrosion inhibition efficiency of this plant's extracts is normally attributed to the presence of complex organic species.

Corrosion of aluminum and its alloys has been a subject of numerous studies due to their importance in the recent civilization. Accordingly, numerous studies concerning the inhibition of aluminum corrosion using organic substances have been conducted [13-16].

Capparis is a flowering plant genus in the family of Capparaceae. These plants are shrubs or lianas and are collectively known as caper shrubs or caper bushes. Capparis species occur over a wide range of habitat in the subtropical and tropical zones. The corrosion inhibition efficiency of Capparis extract is normally attributed to the presence of complex organic species such as Sterols, flavones, oxygenated heterocyclic constituents, alkaloids, and an isothiocyanate glycoside [17-20].

In the present work, weight loss method and electrochemical polarization methods were used to investigate the inhibition of aluminum corrosion by $C$. aegyptia extract in a $1 \mathrm{M} \mathrm{NaOH}$ solution. Weight loss measurement was used to study the effect of inhibitor concentration and temperature on the inhibitor efficiency of C. aegyptia extract on the corrosion aluminum. The surface morphology was analyzed by scanning electron microscopy (SEM) technique.

\section{Experimental}

\subsection{Material preparation}

Pure aluminum (purity 99.999\%) was supplied in the form of a foil of a thickness of $0.5 \mathrm{~mm}$ (Aldrich). The experiments were carried out using rectangular aluminum foil specimens (dimensions: length $=3 \mathrm{~cm}$, width $=1 \mathrm{~cm}$ and thickness $=0.5 \mathrm{~mm}$ ). The aluminum specimens were treated by a mixture of $\mathrm{H}_{3} \mathrm{PO}_{4}\left(85 \mathrm{wt} . \%\right.$ in water) and $\mathrm{HNO}_{3}$ $(15 \mathrm{v} \%)$ at $80^{\circ} \mathrm{C}$ for $30 \mathrm{~s}$, then immersed in $\mathrm{HNO}_{3}$ solution $(50 \% \mathrm{v} / \mathrm{v})$ at $50^{\circ} \mathrm{C}$ for 20 seconds, rinsed well in deionized water and placed in alkaline solution $(40.0 \mathrm{~g} \mathrm{NaOH}$ in $1 \mathrm{~L}$ deionized water) for one minute. The specimens dried well on-air stream and isolated from the outside atmosphere for further use.

\subsection{Preliminary phytochemical screening}

The obtained methanolic extract of the C. aegyptia plant was subjected to different chemical tests for the detection of different Phyto-constituents using standard procedures [21]. Moreover, the presence of these functional groups was confirmed by recording the FTIR spectra for the crude oil using Bruker Tenson 72 spectrometer.

\subsection{Samples preparation and weight loss measurements}

The inhibition efficiency of aluminum in the aqueous solution of sodium hydroxide by using $C$. aegyptia extract as an inhibitor was determined by the gravimetric technique. A $50 \mathrm{~g}$ of dry C. aegyptia powder was refluxed in $250 \mathrm{~mL}$ of $1 \mathrm{M} \mathrm{NaOH}$ solution for $3 \mathrm{~h}$, 
allowed to stand overnight then filtered using Whatman general-purpose filter paper, diam. $90 \mathrm{~mm}$ (Aldrich). The weight loss experiments were carried out using the aluminum foil specimens (total exposed area $=6.4 \mathrm{~cm}^{2}$ ). Specimens were weighed and immersed for different time intervals $(1,2,4$ and 6 hours $)$ at $250^{\circ} \mathrm{C}$ in $15 \mathrm{ml}$ of $1 \mathrm{M} \mathrm{NaOH}$ solutions of the $(C$. aegyptia), and for different concentrations of the extract $(40-440 \mathrm{mg} / \mathrm{L})$. After testing, they were rinsed thoroughly with deionized water, dried, and reweighed. The measurements were carried out at 25,35 and $450^{\circ} \mathrm{C}$ using a water thermostat controlled to $\pm 0.50^{\circ} \mathrm{C}$ and weighed using Electronic Semimicro Balance Sartorius 2024 MP6 with the precision of $\pm 0.1 \mathrm{mg}$. Triplicate determinations were carried out each time.

\subsection{Potentiostatic polarization measurements}

Potentiostatic polarization studies were carried out using an EG\&G (model 264) potentiostat/galvanostat. The current-potential curves were measured using a conventional three-electrode cell. The working electrode was aluminum (a cylindrical rod embedded in Araldite with the exposed surface area of $0.6 \mathrm{~cm}^{2}$ ); the saturated calomel electrode (SCE) was used as a reference and a platinum foil was used as a counter electrode. Polarization was carried out in alkaline solution in the absence and presence of various concentrations of the inhibitor $C$. aegyptia. The current-potential curves were recorded automatically. The polarization was scanned from a potential of $-1000 \mathrm{mV}$ to $0.0 \mathrm{mV}$ (SCE) with a scan rate of $10 \mathrm{mV} \mathrm{s}^{-1}$.

The electrochemical corrosion current density was evaluated using the well-known Stern-Geary equation (Equation 1):

$$
I_{\text {corr }}=\frac{\beta_{\mathrm{a}} \beta_{\mathrm{c}}}{2.303\left(\beta_{\mathrm{a}}+\beta_{\mathrm{c}}\right) \frac{1}{R_{\mathrm{p}}}}
$$

where $I_{\text {corr }}$ is the corrosion current density; $\beta_{\mathrm{a}}$ is the anodic Tafel constant; $\beta_{\mathrm{c}}$ is the cathodic Tafel constant and $R_{\mathrm{p}}$ is the polarization resistance.

Corrosion current density $\left(I_{\text {corr }}\right)$ was estimated from the intercept of cathodic and anodic Tafel lines and the inhibition efficiency $(I \%)$ was calculated by using the following equation (Equation 2) :

$$
I \%=\left(I_{\text {corr }}^{*}-I_{\text {corr }}\right) / I_{\text {corr }}^{*} r
$$

where, $I_{\text {corr }}$ and $I_{\text {corr }}^{*}$ are the corrosion current density with and without the inhibitor, respectively.

\subsection{Scanning electron microscopy (SEM)}

The surface morphology of the aluminum specimens was examined after polishing and after exposure to $1 \mathrm{M} \mathrm{NaOH}$ in the absence and presence of an optimal concentration of 
the inhibitor. The instrument used was FEI Inspect F50 scanning electronic microscope (Netherlands) equipped with a Field Emission Gun (FEG).

\section{Results and discussion}

\subsection{Phytochemical analysis}

Methanolic extract of $C$. aegyptia is investigated as a possible corrosion inhibitor. As shown in Table 1, the methanolic extract was found to contain flavonoids, Anthraquinones, saponin, tannins, and glycosides. It is well-documented that most of these constituents have excellent inhibitive action [22-26].

Table 1. Qualitative analysis of phytochemical compounds in the methanolic extract of C. aegyptia.

\begin{tabular}{cl}
\hline Phytochemical tests & Result \\
\hline Tannins & Positive \\
Flavonoids & Positive \\
Anthraquinones & Positive \\
Saponins & Positive \\
Glycosides & Positive \\
\hline
\end{tabular}

\subsection{Fourier transform infra-red (FTIR) spectroscopy}

IR spectrum was obtained for the extract mixture as shown in Figure 1. Careful inspection of the IR spectra indicate the presence of the following active sites; (i) $\mathrm{O}-\mathrm{H}$ stretching frequency appears at $3409 \mathrm{~cm}^{-1}$; (ii) The aromatic stretching frequency appear at $292 \mathrm{~cm}^{-1}$ and $2852 \mathrm{~cm}^{-1}$; (iii) $-\mathrm{C}=\mathrm{O}$ stretching frequency at $1620 \mathrm{~cm}^{-1}$; (iv) $-\mathrm{C}=\mathrm{C}-$ stretching frequency at $1510 \mathrm{~cm}^{-1}$; (v) $-\mathrm{CH}_{2}$ bending frequency at $1385 \mathrm{~cm}^{-1}$ (vi) $-\mathrm{CH}$ bending frequency at $1272 \mathrm{~cm}^{-1}$ (vii) $-\mathrm{C}=\mathrm{C}$ - bending frequency at $1059 \mathrm{~cm}^{-1}$.

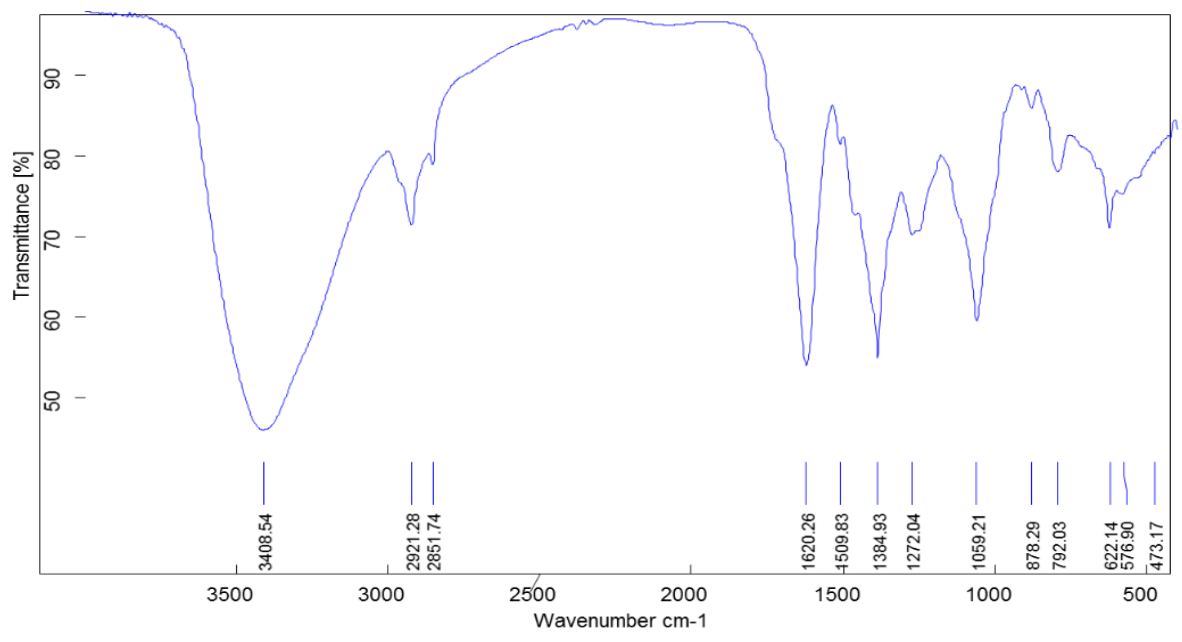

Figure 1. The IR spectra for the C. aegyptia extract. 


\subsection{Weight loss measurements}

\subsubsection{Effect of inhibitor concentration}

The weight loss of aluminum in $1 \mathrm{M} \mathrm{NaOH}$ in the presence and absence of C. aegyptia extract as green inhibitor were tested at $25^{\circ} \mathrm{C}$, at different immersion times $(1 \mathrm{~h}, 2 \mathrm{~h}, 4 \mathrm{~h}$, and $6 \mathrm{~h}$ ), and for different concentrations of the extract $(40-440 \mathrm{mg} / \mathrm{L})$. The weight loss was recorded to the nearest $\pm 0.1 \mathrm{mg}$. The weight loss of the corrosive solution is given by the following equation (Equation 3);

$$
\Delta W=W_{\mathrm{i}}-W_{\mathrm{f}}
$$

where $W_{\mathrm{i}}$ and $W_{\mathrm{f}}$ are the weight losses of the aluminum specimens in the presence and absence of the inhibitors, respectively. Figure 2 shows the variation of the weight loss (mg) of $\mathrm{Al}$ due to corrosion with the immersion time in $1 \mathrm{M} \mathrm{NaOH}$ solution of various concentrations of $C$. aegyptia extract at $25^{\circ} \mathrm{C}$, respectively. Weight loss of aluminum was determined, at various time intervals, in the absence and presence of different concentrations of $C$. aegyptia extract. the weight loss values (mg) of Al decreased as the concentration of the inhibitor increased, $I E$ the corrosion inhibition increases with increasing the extract concentration. This behavior is expected to occur due to the increase in the surface coverage of the metal with the increase of the extract concentration, thus the aluminum surface is efficiently separated from the medium [24-27].

The percentage inhibition efficiency (IE) was calculated using the following equation (Equation 4).

$$
\% I E=\left(w_{0}-w_{\mathrm{i}}\right) / w_{0}
$$

where $w_{0}$ and $w_{\mathrm{i}}$ are weight losses of $\mathrm{Al}$ in the absence and presence of the inhibitor. The percentage of inhibition efficiency (\%IE) of the investigated C. aegyptia crud extract (Table 2). These experiments were Carried out at different time intervals and using different concentrations of the inhibitor at $25^{\circ} \mathrm{C}$. A careful look at these Table 2 indicates that the inhibition efficiency increases with increasing the extract concentration and time. Generally, the adsorption of inhibitor at metal/solution interfaces can markedly change the corrosion resisting properties of metals. The efficiency of organic molecules as good corrosion inhibitors mainly depends on their adsorption ability on the metal surface. This adsorption can occur through the replacement of water molecules by organic inhibitor molecules [27]. 


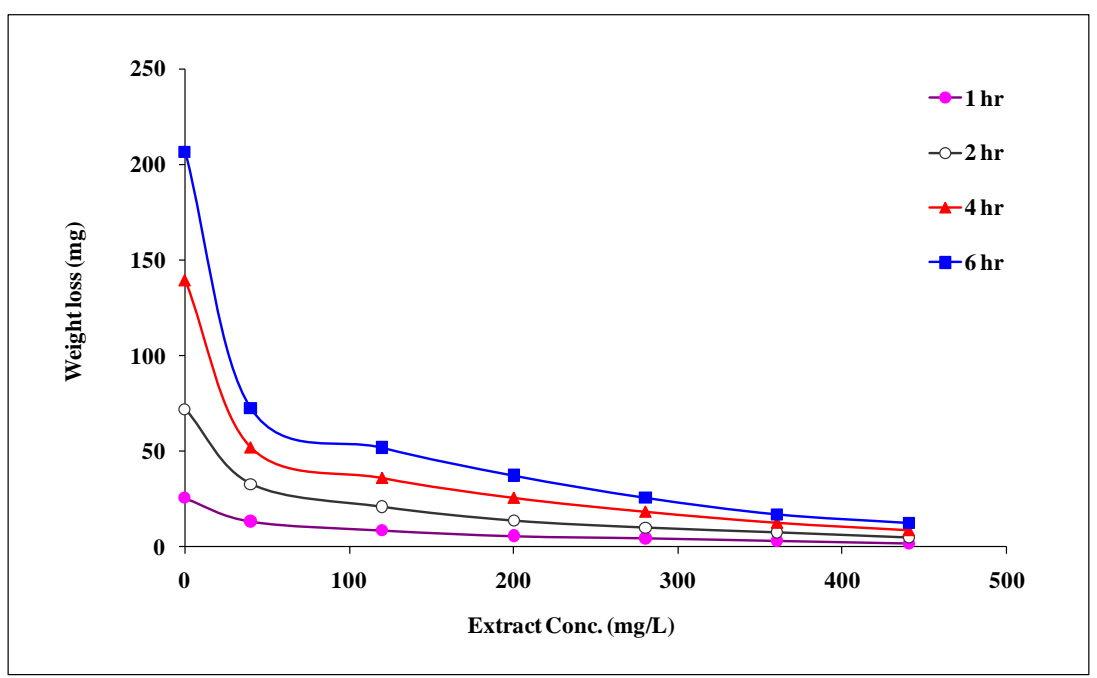

Figure 2. Weight loss variation of aluminum versus C. aegyptia extracts concentration in $1 \mathrm{M}$ $\mathrm{NaOH}$ at $25^{\circ} \mathrm{C}$ at different immersion period.

Table 2. Inhibition efficiencies of $\mathrm{Al}$ in the presence of different concentrations of the inhibitor and at different time intervals at $25^{\circ} \mathrm{C}$.

\begin{tabular}{ccccc}
\hline & \multicolumn{5}{c}{ Inhibition efficiency (\% IE) } \\
\cline { 2 - 5 } Conc. $(\mathbf{p p m})$ & $\mathbf{1 ~ h}$ & $\mathbf{2}$ & $\mathbf{4} \mathbf{~ h}$ & $\mathbf{6 ~ h}$ \\
\hline 40 & 47.1 & 54.2 & 62.7 & 64.9 \\
120 & 65.3 & 70.9 & 74.2 & 74.8 \\
200 & 76.9 & 80.9 & 81.6 & 81.8 \\
280 & 81.1 & 86.0 & 86.8 & 87.4 \\
360 & 86.4 & 89.4 & 91.0 & 91.6 \\
440 & 91.6 & 93.2 & 93.8 & 93.8 \\
\hline
\end{tabular}

\subsubsection{Effect of temperature}

Corrosion rates (CR) of $\mathrm{Al}$ are calculated several experiments were carried out using the same parameters except for temperature, which was changed over the range $\left(25,35,45^{\circ} \mathrm{C}\right)$. The immersion time in these experiments was kept constant also at two hours. The influence of changing the temperature on the corrosion rate of $\mathrm{Al}$ in $1 \mathrm{M} \mathrm{NaOH}$ solutions is presented in Figure 3, the figure reveals that the corrosion rates increase with an increase in temperature. Usually, increasing the temperature accelerates the corrosion process and hence increases the dissolution rate of the metal. However, when inhibition efficiencies are calculated, the reverse was observed, in which, the inhibition efficiency was increased with the increase of temperature Table 3. It is well documented in the literature that, a decrease in inhibition efficiency with the rise in temperature is frequently interpreted as being suggestive of the formation of an adsorption film of physical (electrostatic) nature. The 
reverse effect (our case), corresponding to an increase in inhibition efficiency with a rise in temperature in the presence of inhibitor, suggests a chemisorptions mechanism [27-30].

Table 3 shows the percentage of inhibition efficiencies at various concentrations in $1 \mathrm{M} \mathrm{NaOH}$ for $120 \mathrm{~min}$ immersion period at different temperatures $\left(25-45^{\circ} \mathrm{C}\right)$. The results showed that inhibition efficiency increased as the concentration of inhibitor increases from $40-440 \mathrm{mg} / \mathrm{L}$. The maximum inhibition efficiency of $93.45 \%$ was observed at $45^{\circ} \mathrm{C}$ for $440 \mathrm{mg} / \mathrm{L}$ of extract in basic medium. This behavior is most probably due to an increase in the metal surface area covered by the extract.

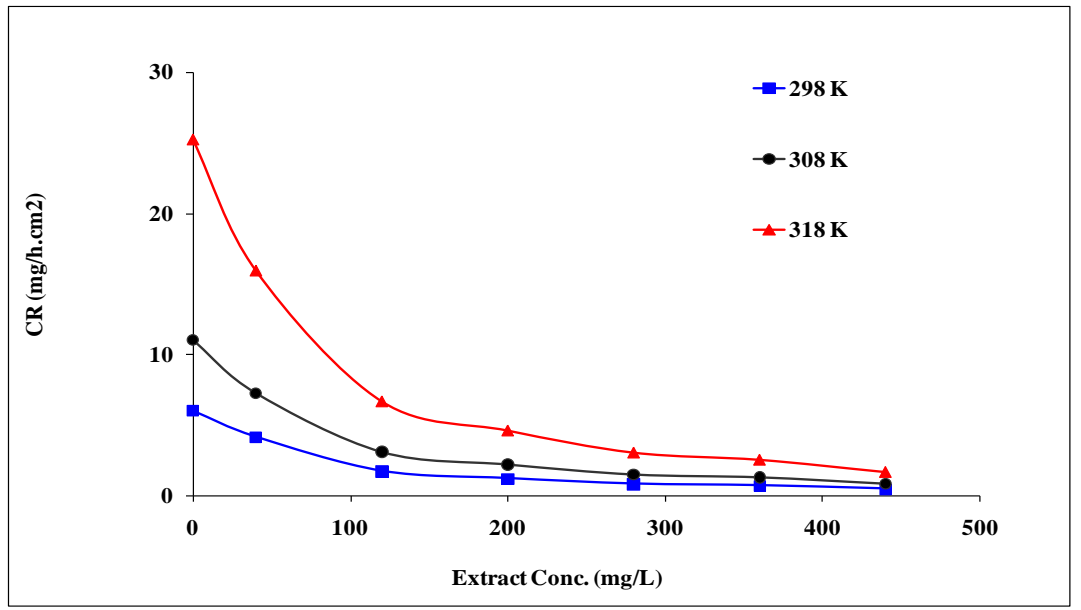

Figure 3. The variation in the corrosion rate of $\mathrm{Al}$ in $1 \mathrm{M} \mathrm{NaOH}$ in the presence of C. aegyptia crud at various temperatures.

Table 3. Inhibition efficiencies of $\mathrm{Al}$ in the presence of different concentrations of the inhibitor at different temperatures at $2 \mathrm{~h}$.

Conc. (ppm)

Inhibition efficiency (\%IE)

\begin{tabular}{cccc} 
& $\boldsymbol{T}=\mathbf{2 9 8} \mathbf{K}$ & $\boldsymbol{T}=\mathbf{3 0 8} \mathbf{~ K}$ & $\boldsymbol{T}=\mathbf{3 1 8} \mathbf{~ K}$ \\
\hline 40 & 30.60 & 34.12 & 36.84 \\
120 & 70.89 & 71.94 & 73.60 \\
200 & 79.51 & 80.00 & 81.79 \\
280 & 85.95 & 86.41 & 87.99 \\
360 & 87.87 & 88.20 & 90.01 \\
440 & 91.77 & 92.30 & 93.45 \\
\hline
\end{tabular}

\subsection{Kinetic and thermodynamic considerations}

By using the Arrhenius law in the temperature range used, a plot of the logarithm of the corrosion rate versus the reciprocal of absolute temperature gives straight lines according to Arrhenius equation (Equation 5): 


$$
R_{\mathrm{c}}=A e^{\frac{-E_{\mathrm{a}}}{R T}}
$$

where $R_{\mathrm{c}}$ is the corrosion rate, $A$ is the constant frequency factor and $E_{\mathrm{a}}$ is the apparent activation energy.

The values of $E_{a}$ were calculated and summarized in Table 4 for the basic medium. The values of the activation energy decrease as the concentration of $C$. aegyptia extract increases.

The value of activation energy $E_{\mathrm{a}}$ is higher in the uninhibited solution compared to the inhabited ones. Analysis of the temperature dependence of inhibition efficiency as well as comparison of corrosion activation energies in the presence of inhibitor gives some insight into the possible mechanism of inhibitor adsorption. A decrease in inhibition efficiency with the rise in temperature, with the analogous increase in corrosion activation energy in the presence of inhibitor compared to its absence, is frequently interpreted as being suggestive of the formation of an adsorption film of physical (electrostatic) nature. The effect, corresponding to an increase in inhibition efficiency with the rise in temperature and lower activation energy in the presence of inhibitor, suggests a chemisorption mechanism [27-30]. From the foregoing, the trend for the extracts of C. aegyptia suggests a predominant effect chemisorption of inhibiting species $1 \mathrm{M} \mathrm{NaOH}$.

Thermodynamic parameters of the corrosion process play an important role in defining the spontaneity of metal conversion into corrosion products. Thermodynamic parameters of activation for corrosion process (enthalpy $(\Delta H)$, free energy $(\Delta G)$ and entropy $(\Delta S)$ ) were calculated by using an alternative formulation of the Arrhenius equation is the transition state equation (Equation 6):

$$
R_{\mathrm{c}}=\frac{K_{\mathrm{b}} T}{h} e^{\left(\Delta S^{*} / R\right)} e^{\left(-\Delta H^{*} / R T\right)}
$$

where $h$ is Planck's constant, $K_{\mathrm{b}}$ Boltzmann's constant, $\Delta S^{*}$ is the entropy of activation and $\Delta H^{*}$ is the enthalpy of activation.

Table 4. Corrosion rates $\left(\mathrm{mg} / \mathrm{h} \cdot \mathrm{cm}^{2}\right)$ and activation energies at various temperatures in $1 \mathrm{M} \mathrm{NaOH}$.

\begin{tabular}{cccccc}
\hline Conc. $(\mathbf{m g} / \mathbf{L})$ & $\begin{array}{c}\boldsymbol{C R} \\
(\mathbf{2 9 8} \mathbf{K})\end{array}$ & $\begin{array}{c}\boldsymbol{C R} \\
(\mathbf{3 0 8} \mathbf{K})\end{array}$ & $\begin{array}{c}\boldsymbol{C R} \\
(\mathbf{3 1 8 ~ K})\end{array}$ & $\boldsymbol{R}^{\mathbf{2}}$ & $\boldsymbol{E}_{\mathbf{a}}(\mathbf{k J} / \mathbf{m o l})$ \\
\hline 0 & 5.992 & 11.046 & 25.267 & 0.989 & 56.59 \\
40 & 4.158 & 7.277 & 15.958 & 0.987 & 52.87 \\
120 & 1.744 & 3.100 & 6.669 & 0.990 & 52.75 \\
200 & 1.228 & 2.209 & 4.600 & 0.993 & 51.97 \\
280 & 0.842 & 1.502 & 3.033 & 0.994 & 50.44 \\
360 & 0.727 & 1.303 & 2.525 & 0.997 & 49.02 \\
440 & 0.493 & 0.850 & 1.655 & 0.994 & 47.62 \\
\hline
\end{tabular}


According to this equation, a plot of $\log \left(R_{\mathrm{c}} / T\right)$ against $(1 / T)$ gives a straight line from which the values of $\Delta H^{*}$ and $\Delta S^{*}$ are calculated and listed in Table 5 for a basic medium

Absolute values of enthalpy of activation decreased from 54.03 to $45.06 \mathrm{~kJ} / \mathrm{mole}$ ongoing form the uninhibited solution to highest inhibitory concentration $(440 \mathrm{mg} / \mathrm{L})$ in $1 \mathrm{M} \mathrm{NaOH}$ solution, values of enthalpy of activation for the inhibited solutions are lower than that of the uninhibited solution followed by a continuous decrease with the increase of inhibitor concentration, indicating that the inhibitory action in solution occurs via chemical adsorption. However, values of enthalpy in this study are larger than the common physical adsorption heat, but smaller than the common chemical adsorption heat $[31,32]$, probably meaning that both physical and chemical adsorption take place (i.e. comprehensive adsorption). The adsorption heat approached the general chemical reaction heat, the chemical adsorption might occur accompanied by physical adsorption (electrostatic interaction).

The entropy of activation $\left(\Delta S^{*}\right)$ in the absence and presence of the inhibitor has negative values. This indicates that the activated complex in the rate-determining step represents an association rather than dissociation, meaning that, a decrease in disordering takes place on going from reactants to the activated complex $[33,34]$. The $\Delta S^{*}$ shifts to more negative values (more ordered behavior) with increasing inhibition efficiency and this was more pronounced in the case of $\mathrm{NaOH}$ inhibited solutions. This can be explained that the inhibitor species may involve in the activated complex of the corrosion reaction leading to more ordered systems.

Table 5. Enthalpy and Entropy values of the reaction with various concentrations of the C. aegyptia extract in $1 \mathrm{M} \mathrm{NaOH}$.

\begin{tabular}{cccc}
\hline Inhibition conc. $(\mathbf{m g} / \mathbf{L})$ & $\boldsymbol{R}^{\mathbf{2}}$ & $\Delta \boldsymbol{S}^{*}(\mathbf{k J} / \mathbf{m o l} \cdot \mathbf{K})$ & $\Delta \boldsymbol{H}^{*}(\mathbf{k J} / \mathbf{m o l})$ \\
\hline 0 & 0.988 & -0.081 & 54.03 \\
40 & 0.986 & -0.096 & 50.32 \\
120 & 0.989 & -0.104 & 50.19 \\
200 & 0.993 & -0.109 & 49.41 \\
280 & 0.994 & -0.117 & 47.88 \\
360 & 0.997 & -0.123 & 46.47 \\
440 & 0.993 & -0.131 & 45.06 \\
\hline
\end{tabular}

\subsection{Adsorption behavior}

The adsorption isotherm can be determined if the inhibitor effect is due mainly to the adsorption on a metallic surface (i.e. to its blocking). The inhibitory action of C. aegyptia extract toward the basic corrosion of aluminum could be attributed to the adsorption of its 
components into the aluminum surface. The adsorbed layer acts as a barrier between the metal surface and the aggressive solution leading to a decrease in the corrosion rate.

The values of the amount of inhibitor adsorbed from the solution, $Q_{\text {ads }}$, on the aluminum specimen in the presence of inhibitor are estimated by the following equation (Equation 7):

$$
Q_{\text {ads }}=2.303 R\left[\log \left(\frac{\theta_{2}}{1-\theta_{2}}\right)-\log \left(\frac{\theta_{1}}{1-\theta_{1}}\right)\right]\left[\frac{T_{1} T_{2}}{T_{2}-T_{1}}\right]
$$

where $R$ is the gas constant, $\theta_{1}$ and $\theta_{2}$ are the degree of surface coverage at temperatures $T_{1}$ $(324 \mathrm{~K})$ and $T_{2}(335 \mathrm{~K})$ respectively.

The calculated values of $Q_{\mathrm{ads}}$ are found to be ranged from 1.0 to $2.0 \mathrm{~kJ} \mathrm{~mol}^{-1}$ for basic medium. The positive sign of $Q_{\mathrm{ads}}$ indicates an increase in efficiency at high temperatures [6-13].

The experimental data for the tested inhibitor C. aegyptia in basic solutions have been applied to different adsorption isotherms. The best correlation among the experimental results from the adsorption of $C$. aegyptia extract on aluminum surface fitted Langmuir adsorption isotherm equation.

The adsorption of C. aegyptia extract molecules obeys the Langmuir adsorption isotherm which is expressed by equation (Equation 8):

$$
\log (C / \theta)=-\log K_{\text {ads }}+\log C
$$

Where $C$ is the inhibition concentration in terms of ppm and $K$ is the equilibrium constant for the adsorption process of the inhibitor molecules on the metal surface. The plot of the $\log (C / \theta)$ vs $\log C$ fitted the experimental data for the basic solution as shown in Figure 8.

The equilibrium constants, $K_{\mathrm{ads}}$, for the adsorption of $C$. aegyptia extract on aluminum in basic solution at different temperatures estimated from the regression equation of the linear plot of Figure 4 are summarized in Table 6.

Table 6. Langmuir adsorption parameters for the adsorption of C. aegyptia extract on aluminum in the basic medium for $120 \mathrm{~min}$ immersion period at different temperatures.

\begin{tabular}{cccc}
\hline Temperature $(\mathbf{K})$ & $\boldsymbol{K}_{\text {ads }}$ & $\boldsymbol{\Delta}_{\text {ads }}(\mathbf{k J} / \mathbf{m o l})$ & $\boldsymbol{R}^{\mathbf{2}}$ \\
\hline 298 & 0.018 & -0.04 & 0.9993 \\
308 & 0.019 & -0.12 & 0.9990 \\
318 & 0.020 & -0.31 & 0.9995 \\
\hline
\end{tabular}




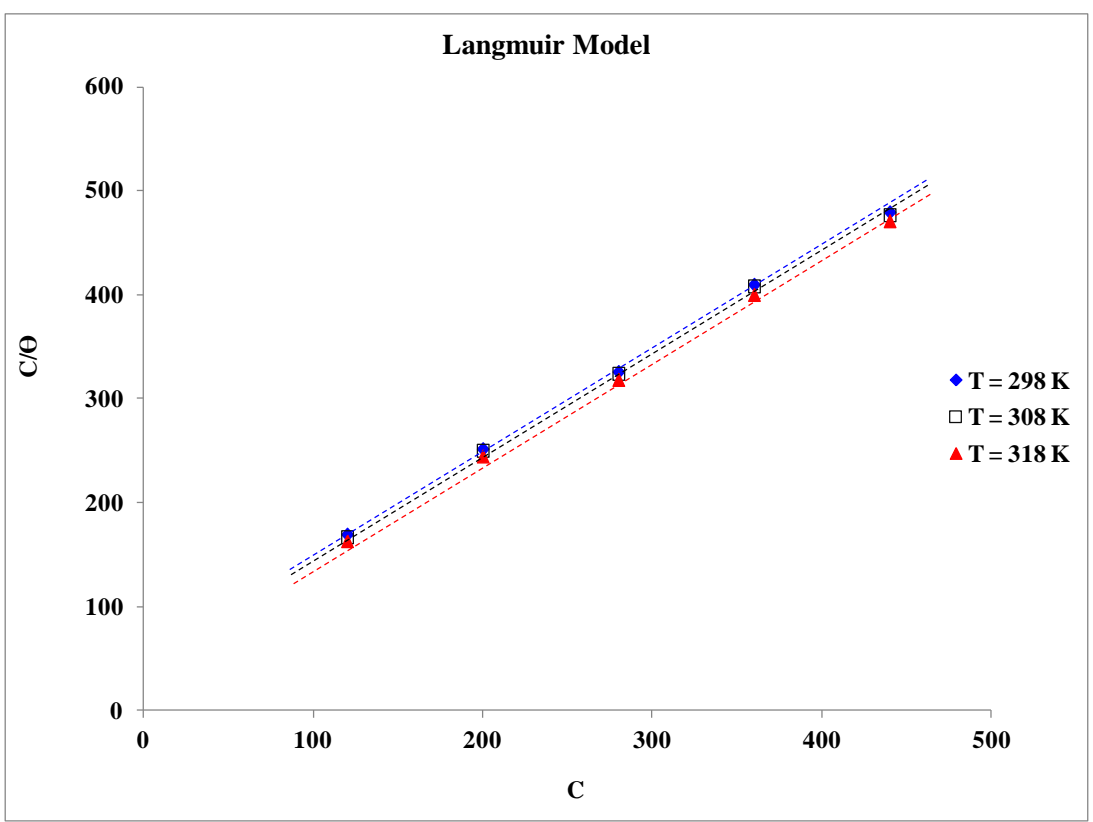

Figure 4. Langmuir adsorption model on the aluminum surface of $C$. aegyptia extracts in $1 \mathrm{M}$ $\mathrm{NaOH}$ solution for 2 hours at different temperatures.

Furthermore, it has been noticed that the value of $K_{\text {ads }}$ increases with increasing temperature, indicating that the adsorption of inhibitor molecules on the aluminum surface was favorable at higher temperatures. Such results imply activation that the interactions between the adsorbed molecules and the metal surface become stronger as temperature increased up to $45^{\circ} \mathrm{C}$, in this study. This result explains the increase in the inhibition efficiency with increasing temperature. However, the low values reported for the free energy change $\Delta G_{\text {ads }}$, confirm the physisorption mechanism of the tested C. aegyptia inhibitor on the aluminum surface.

The experimental data for the tested inhibitor has been applied to Temkin adsorption isotherm equation (Equation 9);

$$
e^{a \theta}=K C
$$

Figure 5 show a plot of $\theta$ versus $\log C$ which was made from the above Temkin equation. A linear graph was obtained which confirmed Temkin adsorption isotherm for the adsorption of the extract on the surface of the metal. The fitting was excellent for the basic medium $\left(R^{2}>0.99\right)$. The $K_{\text {ads }}$ and $\Delta G_{\text {ads }}$ values were evaluated and presented in Table 7.

The relationship between the equilibrium constant $K$ of adsorption and the free energy of adsorption $\Delta G_{\text {ads }}$ is given by equation (Equation 10);

$$
\Delta G_{\text {ads }}=-2.303 R T \log (55.5 K)
$$

Values of free energy of adsorption of $C$. aegyptia crude on the aluminum surface were calculated from the plot of the isotherms in Figure 5 calculated values of $\Delta G_{\text {ads }}$ are recorded in Table 7 these values are negative. For the basic medium, the values were as 
follows; $-9.68,-10.18$ and $-10.70 \mathrm{~kJ} / \mathrm{mol}$ at 298,308 and $318 \mathrm{~K}$, respectively. The values obtained indicate that adsorption of crude is spontaneous and occurs via physical adsorption mechanism. Generally, values of $\Delta G_{\text {ads }}$ up to $-20 \mathrm{~kJ} / \mathrm{mol}$ (as obtained in this study), while values more negative than $-40 \mathrm{~kJ} / \mathrm{mol}$ signify chemical adsorption [6-13].

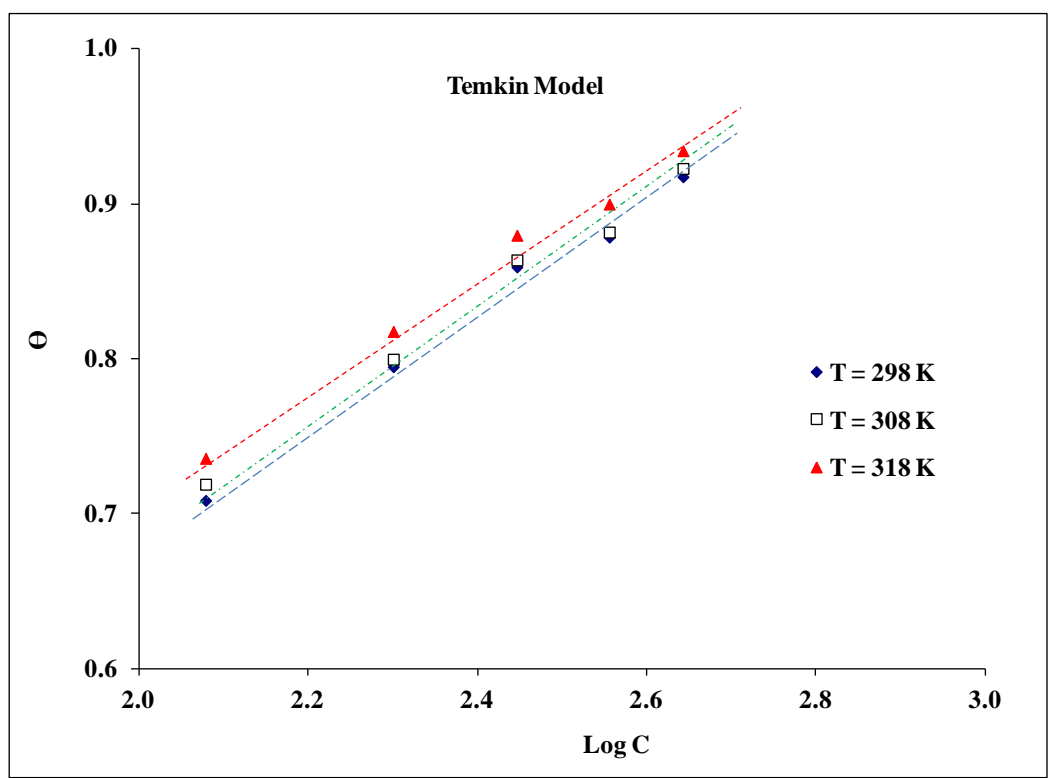

Figure 5. Temkin adsorption isotherm plot as $\theta$ against $\log C$ for $C$. aegyptia extract at different temperatures for aluminum corrosion in $1 \mathrm{M} \mathrm{NaOH}$.

Table 7. Temkin adsorption parameters.

\begin{tabular}{cccc}
\hline Temperature $(\mathbf{K})$ & $\boldsymbol{K}_{\text {ads }}$ & $\Delta \boldsymbol{G}_{\text {ads }}(\mathbf{k J} / \mathbf{m o l})$ & $\boldsymbol{R}^{\mathbf{2}}$ \\
\hline 298 & 0.896 & -9.68 & 0.9910 \\
308 & 0.959 & -10.18 & 0.9910 \\
318 & 1.029 & -10.70 & 0.9920 \\
\hline
\end{tabular}

\subsection{Potentiostatic polarization measurements}

The effect of $C$. aegyptia extract on the corrosion behavior of aluminum electrode in $1 \mathrm{M}$ $\mathrm{NaOH}$ solution has been studied by polarization measurements. The Tafel plot data are graphed as potential versus the logarithm of the measured current as shown in Figure 6.

The electrochemical corrosion parameters including corrosion potential $\left(E_{\text {corr }}\right)$, corrosion current density $\left(I_{\text {corr }}\right)$, anodic Tafel constant $\left(\beta_{\mathrm{a}}\right)$, cathodic Tafel constant $\left(\beta_{\mathrm{c}}\right)$ and inhibition efficiency $(I \%)$ were calculated from the polarization curves of aluminum in the absence and presence of various concentrations of inhibitor in $1 \mathrm{M}$ of $\mathrm{NaOH}$ then summarized in Table 8 . The data in Table 8 show that the corrosion current density $\left(I_{\text {corr }}\right)$ is markedly reduced as the concentration of inhibitor increases, which indicates that the C. aegyptia has a pronounced corrosion inhibition effect of aluminum in these media. 
From the shape of the polarization curve (Figure 6), they are obvious that both anodic and cathodic reactions are inhibited. They are evident from the data shown in Table 8. that as the concentration of the inhibitor increases, the corrosion potential $\left(E_{\text {corr }}\right)$ is slightly changing. Moreover, the values of both anodic $\left(\beta_{\mathrm{a}}\right)$ and cathodic $\left(\beta_{\mathrm{c}}\right)$ Tafel constants are strongly changed in the presence of the inhibitor $(C$. aegyptia). This confirms the mixedmode (anodic and cathodic) inhibition action of the $C$. aegyptia.

The anodic Tafel constant $\left(\beta_{\mathrm{a}}\right)$ is greater than the cathodic $\left(\beta_{\mathrm{c}}\right)$ Tafel constant at all inhibitor's concentrations suggesting that the effect of the inhibitors on the anodic polarization is more pronounced than that on cathodic polarization (Table 8).

It was reported that the presence of polyphenol compounds inhibits the corrosion by controlling both the anodic and cathodic reactions

Furthermore, an inspection of Table 8. reveals that; current densities $\left(I_{\text {corr }}\right)$ decrease considerably by the addition of the extract to the basic solution concerning the blank solution, indicate that the extract retards the rate of corrosion. Also, a significant decrease in the corrosion current $\left(I_{\text {corr }}\right)$ and corrosion rate accompanied by an increase in the polarization resistance (RP) value, which is evident that the inhibition efficiency increased with extract concentration increased and reaching a maximum at $440 \mathrm{ppm}$. The obtained values of inhibition efficiency $(I \%)$ from polarization studies were in good agreement with those obtained from the weight loss study with a small variation. The results of both weight loss and polarization methods revealed that the $C$. aegyptia provide very good protection to aluminum against corrosion in basic medium. This can be attributed to the relative stability of the C. aegyptia film that formed on the surface of aluminum [22, 24].

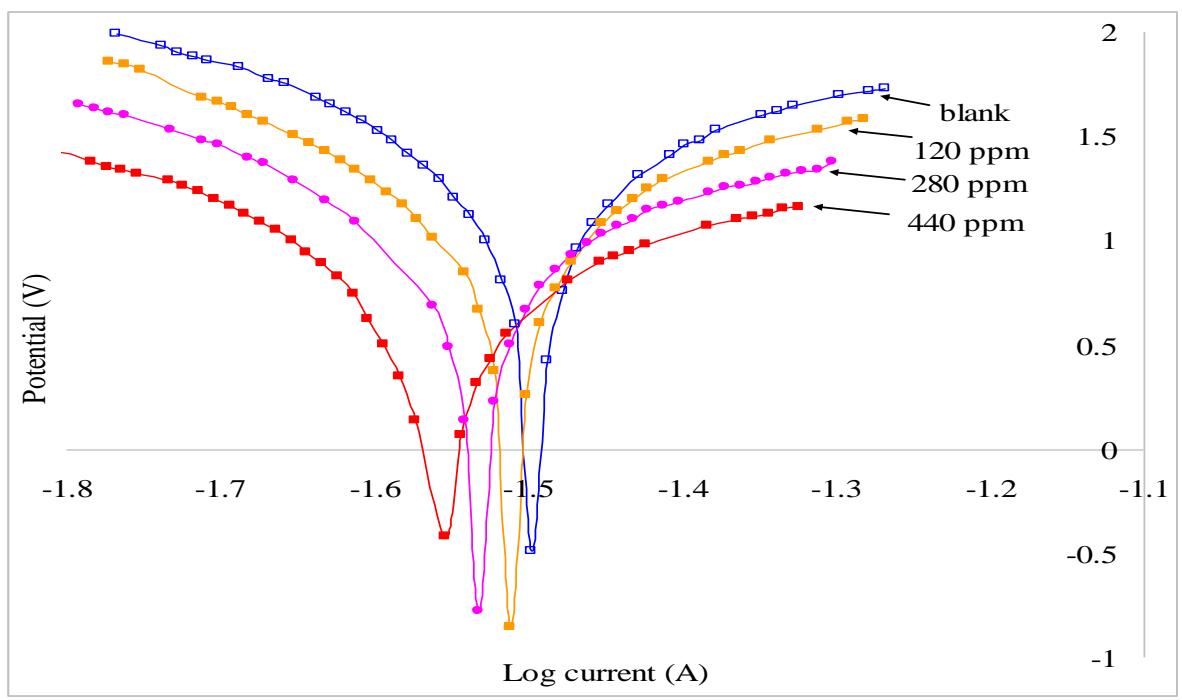

Figure 6. Polarization anodic and cathodic curves of aluminum in the absence and presence of various concentrations of $C$. aegyptia in $1 \mathrm{M} \mathrm{NaOH}$. 
Table 8. Electrochemical corrosion parameters of Aluminum in the absence and presence of various concentrations of inhibitor $C$. aegyptia in $1 \mathrm{M} \mathrm{NaOH}$.

\begin{tabular}{cccccccc}
\hline $\begin{array}{c}\text { Extract conc } \\
(\mathbf{m g} / \mathbf{L})\end{array}$ & $\begin{array}{c}\boldsymbol{E}_{\text {corr }} \\
(\mathbf{m V} / \mathbf{S C E})\end{array}$ & $\begin{array}{c}\boldsymbol{I}_{\mathbf{c o r r}} \\
\left(\boldsymbol{\mu} \mathbf{A} / \mathbf{c m}^{\mathbf{2}}\right)\end{array}$ & $\begin{array}{c}\boldsymbol{\beta}_{\mathbf{a}} \\
(\mathbf{m V / d e c})\end{array}$ & $\begin{array}{c}\boldsymbol{\beta}_{\mathbf{c}} \\
(\mathbf{m V / d e c})\end{array}$ & $\begin{array}{c}\boldsymbol{R}_{\mathbf{p}} \\
(\mathbf{O h m})\end{array}$ & $\boldsymbol{I}(\boldsymbol{\%})$ & $\begin{array}{c}\boldsymbol{C R} \\
\mathbf{m m} / \mathbf{y}\end{array}$ \\
\hline Blank & -149.89 & 6.546 & 157 & 50 & 4.924 & - & 71.40 \\
120 & -150.1 & 2.731 & 116 & 34 & 7.499 & 58.27 & 57.35 \\
280 & -154.8 & 1.367 & 94 & 28 & 15.24 & 79.11 & 14.91 \\
440 & -155.9 & 0.664 & 48 & 36 & 16.73 & 89.85 & 7.30 \\
\hline
\end{tabular}

\subsection{Scanning electron microscope (SEM)}

a)

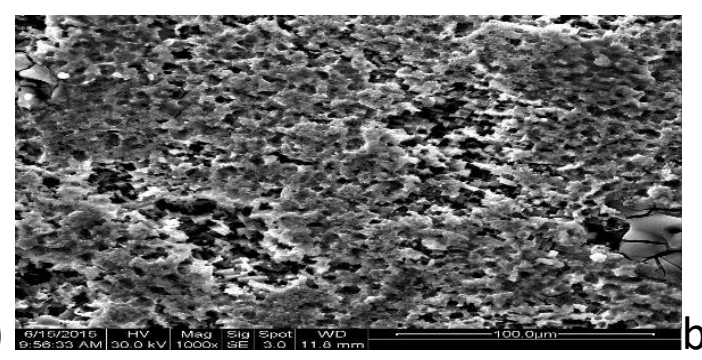

b)

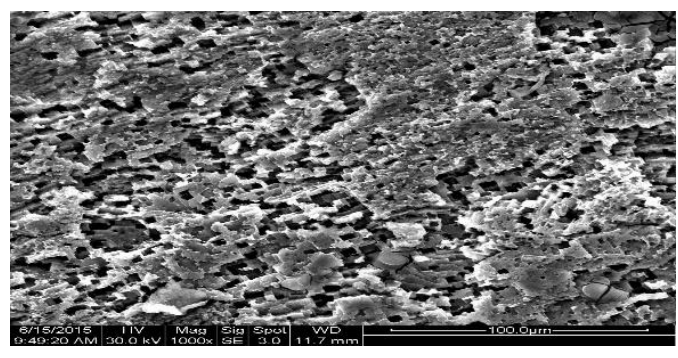

c)

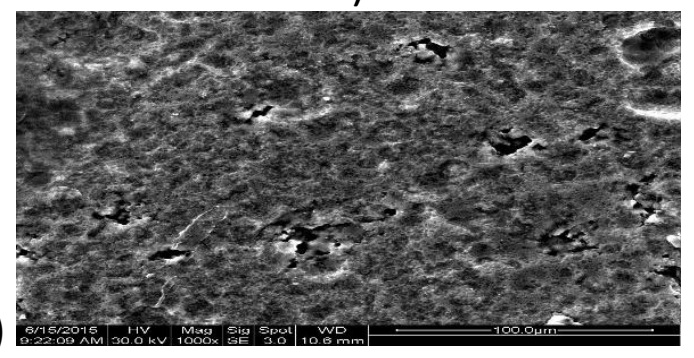

Figure 7. Scanning electron micrograph of plain aluminum in basic medium (a) aluminum in $1 \mathrm{M} \mathrm{NaOH}$ at $25^{\circ} \mathrm{C}$ (b) aluminum in $1 \mathrm{M} \mathrm{NaOH}$ in the presence of $120 \mathrm{ppm} \mathrm{C.} \mathrm{aegyptia} \mathrm{at}$ $25^{\circ} \mathrm{C}$ (c) aluminum in $1 \mathrm{M} \mathrm{NaOH}$ in the presence of $440 \mathrm{ppm} \mathrm{C}$. aegyptia at $25^{\circ} \mathrm{C}$.

Figure 7(a) shows uniform severe corrosion in the absence of inhibitor, and the forming of adherent amorphous corrosion products. The appearance of such corroded areas may be attributed to the dissolution of the alumina layer due to the aggressive attack of $\mathrm{OH}^{-}$anions and the increased alkalinity of the solution in the vicinity of the surface [7-9]. However, the SEM obtained for aluminum in presence of inhibitor showed that the metal surface is partially covered with inhibitor giving it a reasonable degree of protection and it is obvious that the surface is covered with an inhibitor in presence of sodium hydroxide (Figure 7(b) and (c)). The formation of an adsorbed protective film of the inhibitor molecules on the aluminum surface is also confirmed by scanning electron micrographs in Figure $7(\mathrm{c})$, which proves that $C$. aegyptia acts as a good inhibitor at basic solutions. 


\section{Conclusion}

The $C$. aegyptia extract was successfully applied as a corrosion inhibitor on the surface of aluminum in an alkaline solution. The inhibition efficiency increases with an increase in the concentration of the C. aegyptia to attain a value of $93.8 \%$ in the basic medium at the highest inhibitor concentration $440 \mathrm{ppm}$ at $25^{\circ} \mathrm{C}$. Results indicated that the plant extract acts as a good inhibitor in basic media. Besides, it is found that the inhibition efficiency increases with temperature increasing. The values of activation energies $\left(E_{\mathrm{a}}\right)$ for the inhibited solutions were less than those of an un-inhibited solution. Interpretations of various thermodynamic, kinetic and electrochemical results indicate the presence of a mixed mechanism for the adsorption of the inhibitor molecules over the aluminum surface. The inhibitor molecules involve both physical and chemical adsorption.

\section{Acknowledgments}

We thank the Deanship of Scientific Research and Graduate Studies of Yarmouk University, Irbid, Jordan.

\section{References}

1. E.E. Oguzie, Studies on the inhibitive effect of Occimum viridis extract on the acid corrosion of mild steel, Mater. Chem. Phys., 2006, 99, no. 2-3, 441-446. doi: 10.1016/j.matchemphys.2005.11.018

2. E.E. Oguzie, Corrosion inhibitive effect and adsorption behaviour of Hibiscus sabdariffa extract on mild steel in acidic media, Port. Electrochim. Acta, 2008, 26, no. 3, 303-314. doi: 10.4152/pea.200803303

3. H.I. Al-Itawi, G.M. Al-Mazaideh, A.E. Al-Rawajfeh, A.M. Al Ma'abreh and A. Marashdeh, The effect of some green inhibitors on the corrosion rate of $\mathrm{Cu}, \mathrm{Fe}$ and Al metals, Int. J. Corros. Scale Inhib., 2019, 8, no. 2, 199-211. doi: 10.17675/23056894-2019-8-2-3.

4. P.C. Okafor, U.J. Ekpe, E.E. Ebenso, E.M. Umoren and K.E. Leizou, Inhibition of mild steel corrosion in acidic medium by Allium sativum extracts, Bull. Electrochem., 2005, 21, no. 8, 347-352.

5. N.C. Subramanyam, B.S. Sheshadri and S.M. Mayanna, Thiourea and substituted thioureas as corrosion inhibitors for aluminum in sodium nitrite solution, Corros. Sci., 1993, 34, no. 4, 563-571. doi: 10.1016/0010-938X(93)90272-I

6. E.M. Nawafleh, T.T. Bataineh, M.K. Irshedat, M.A. Al-Qudah and S.T. Abu Orabi, Inhibition of aluminum corrosion by Salvia Judica extract, Res. J. chem. Sci., 2013, 3, no. $8,68-72$.

7. T.T. Bataineh, M.A. Al-Qudah, E.M. Nawafleh and N.A.F. Al-Rawashdeh, Sinapis alba extract as green corrosion inhibitor for aluminum in alkaline media, Int. J. Electrochem. Sci., 2014, no. 9, 3543-3557. 
8. T.T. Bataineh, M.A. Al-Qudah, E.M. Nawafleh and A.M. Ajlouni, Corrosion control of aluminum alloy in alkaline solution using leave extract of plumbago Europaea, Jordan J. Chem., 2013, 8, no. 3, 169-178.

9. T.M. Al Shboul, T.M. Jazzazi, T.T. Bataineh, M.A. Al-Qudah and A.I. Alrawashdeh, Inhibition of corrosion of aluminium in $\mathrm{NaOH}$ solution by leave extract of Mesembryanthemum nodiflorum, Jordan J. Chem., 2014, 9, no. 3, 149-158.

10. M.K. Irshedat, E.M. Nawafleh, T.T. Bataineh, R. Muhaidat and M.A. Al-Qudah, Investigations of the inhibition of aluminum corrosion in $1 \mathrm{M} \mathrm{NaOH}$ solution by Lupinus varius l. extract, Port. Electrochim. Acta, 2013, 31, no. 1, 1-10.

11. E. Nawafleh, M. Irshedat, T. Bataineh, R. Muhaidat, M.A. Al-Qudah and A. Alomary, The effects of Inula viscosa extract on corrosion of copper in $\mathrm{NaOH}$ solution, Res. J. Chem. Sci., 2012, 2, no. 9, 37-41.

12. F. Wedian, M.A. Al-Qudah and G.M. Al-Mazaideh, Corrosion inhibition of copper by Capparis spinosa $l$. extract in strong acidic medium: experimental and density functional theory, Int. J. Electrochem. Sci., 2017, no. 12, 4664-4676. doi: $\underline{10.20964 / 2017.06 .47}$

13. F. Wedian, M.A. Al-Qudah and A.N. Abu-Baker, The effect of Capparis spinosa l. extract as a green inhibitor on the corrosion rate of copper in a strong alkaline solution, Port. Electrochim. Acta, 2016, 34, no. 1, 39-51. doi: 10.4152/pea.201601039

14. B.N. Subedi, K. Amgain, S. Joshi and J. Bhattarai, Green approach to corrosion inhibition effect of Vitex negundo leaf extract on aluminum and copper metals in biodiesel and its blend, Int. J. Corros. Scale Inhib., 2019, 8, no. 3, 744-759. doi: 10.17675/2305-6894-2019-8-3-21

15. A. Ruosan and N.A.F. Al-Rawashdeh, Magnetic field effects on inhibition of aluminium corrosion by cationic surfactant in acidic solution, Corros. Eng. Sci. Tech., 2006, 41, no. 3, 235-239. doi: 10.1179/174327806X132150

16. N.A.F. Al-Rawashdeh and A.K. Maayta, Cationic surfactant as corrosion inhibitor for aluminum in acidic and basic solutions, Anti-Corros. Meth. Mater., 2005, 52, no. 3, 160-166. doi: https://doi.org/10.1108/00035590510595157

17. M.M. Al-Abdallah, A.K. Maayta, M.A. Al-Qudah and N.A.F. Al-Rawashdeh, Corrosion behavior of copper in chloride media, Open Corrosion J., 2009, no. 2, 7177. doi: $10.2174 / 1876503300902010071$

18. V.U. Ahmad, Further studies on the chemical constituents of Pakistani medicinal plants, Stud. Org. Chem., 1986, 26, no. 1, 1-23.

19. V.U. Ahmad, S. Arif, A.R. Amber, M.A. Nasir and K.U. Ghani, A new alkaloid from root bark of Capparis decidua, Z. Naturforsch. B Chem. Sci., 1986, no. 41b, 10331035. doi: $10.1515 / \mathrm{znb}-1986-0818$

20. V.U. Ahmad, S. Arif, A.R. Amber and K. Fizza, Capparisinine, a new alkaloid from Capparis decidua, Liebigs Ann. Chem., 1987, no. 2, 161-162. doi: $\underline{10.1002 / j l a c .198719870209}$ 
21. T.R. Juneja, K.N. Gaind and A.S. Panesar, Capparis decidua. Study of isothiocyanate glucoside, Res. Bull. Panjab. Univ. Sci., 1970, no. 21, 519-521.

22. J.B. Harborne, Phytochemical methods, Chapman Hall, London, 1998, 60-66.

23. S.A. Umoren, O. Ogbobe and E.E. Ebenso, The adsorption characteristic synergistic inhibition between polyethylene glycol and halide ions for the corrosion of mild steel in acidic medium, Bull. Electrochem., 2006, 22, no. 4, 155-157. doi: 10.1016/j.desal.2008.09.005

24. M.R. Saleh, A.A. Ismail and A.A. El Hosary, Corrosion inhibition by naturally occurring substances. vii. the effect of aqueous extracts of some leaves and fruit peels on the corrosion of steel, $\mathrm{Al}, \mathrm{Zn}$ and $\mathrm{Cu}$ in acids, Br. Corros. J., 1982, 17, no. 3, 131135. doi: $10.1179 / 000705982798274345$

25. I.B. Obot and N.O. Obi-Egbedi, Ipomoea Involcrata as an ecofriendly inhibitor for aluminium in alkaline medium, Port. Electrochim. Acta, 2009, 27, no. 4, 517-524. doi: 10.4152/pea.200904517

26. K. Srivastava, P. Srivastava, Studies on plant materials as corrosion inhibitors, $\mathrm{Br}$. Corros. J., 1981, 16, no. 4, 221-223. doi: $10.1179 / 000705981798274788$

27. A.A. Hosary, M.R. Saleh and M.A. Shams El Din, Corrosion inhibition by naturally occurring substances-I. The effect of Hibiscus subdariffa (karkade) extract on the dissolution of Al and Zn, Corros. Sci., 1972, 12, no. 12, 897-904. doi: 10.1016/S0010938X(72)80098-2

28. M.S. El-Sayed, R.M. Erasmus and J.D. Comins, Inhibition of copper corrosion in acidic chloride pickling solutions by 5-(3-aminophenyl)-tetrazole as a corrosion inhibitor, Corros. Sci., 2008, 50, no. 1, 3439-3445. doi: 10.1016/j.corsci.2008.10.002

29. A. Popova, E. Sokolova, S. Raicheva and M. Christov, AC and DC study of the temperature effect on mild steel corrosion in acid media in the presence of benzimidazole derivatives, Corros. Sci., 2003, no. 45, 33-58. doi: 10.1016/S0010938X(02)00072-0

30. E. Oguzie, G. Onuoha and A. Onuchukwu, Inhibitory mechanism of mild steel corrosion in $2 \mathrm{M}$ sulphuric acid solution by methylene blue dye, Mater. Chem. Phys., 2005, no. 89, 305-311. doi: 10.1016/j.matchemphys.2004.09.004

31. L.A. Nnanna, B.N. Onwuagba, I.M. Mejeha and K.B. Okeoma, Inhibition effects of some plant extracts on the acid corrosion of aluminum alloy, Afr. J. Pure Appl. Chem., 2010, no. 4, 11-16.

32. G. Mu, X. Li and G. Liu, Synergistic inhibition between tween 60 and $\mathrm{NaCl}$ on the corrosion of cold rolled steel in 0.5 M sulfuric acid, Corros. Sci., 2005, no. 47, 19321952. doi: $10.1016 /$ j.corsci.2004.09.020

33. E.A. Noor, Temperature effects on the corrosion inhibition of mild steel in acidic solutions by aqueous extract of Fenugreek Leaves, Int. J. Electrochem. Sci., 2007, no. 2, 996-1017. 
34. S.S. Abd El-Rehim, H.H. Hassan and M.A. Amin, Corrosion inhibition of aluminum by 1,1(lauryl amido)propyl ammonium chloride in $\mathrm{HCl}$ solution, Mater. Chem. Phys., 2001, no. 70, 64-72. 10.1016/S0254-0584(00)00468-5

35. M.K. Gomma and M.H. Wahdan, Schiff bases as corrosion inhibitors for aluminium in hydrochloric acid solution, Mater. Chem. Phys., 1995, no. 39: 209-213. doi: $\underline{10.1016 / 0254-0584(94) 01436-K}$

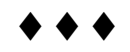

